\title{
Comparison of panoramic radiography and cone-beam computed tomography for assessing radiographic signs indicating root protrusion into the maxillary sinus
}

\author{
Yun-Hoa Jung $\mathbb{D}^{1}$, Bong-Hae Cho(D) ${ }^{1}$, Jae Joon Hwang $\mathbb{D}^{1, *}$ \\ ${ }^{1}$ Department of Oral and Maxillofacial Radiology, School of Dentistry, Pusan National University, Yangsan, Korea
}

\section{ABSTRACT}

Purpose: This study investigated correlations between findings on panoramic radiographs and cone-beam computed tomography (CBCT) to assess the relationship between the maxillary sinus floor and the roots of maxillary posterior teeth. In addition, radiographic signs indicating actual root protrusion into the maxillary sinus were evaluated on panoramic radiographs.

Materials and Methods: Paired panoramic radiographs and CBCT images from 305 subjects were analyzed. This analysis classified 2,440 maxillary premolars and molars according to their relationship with the maxillary sinus floor on panoramic radiographs and CBCT images. In addition, interruption of the sinus floor was examined on panoramic radiographs.

Results: Root protrusion into the maxillary sinus occurred most frequently in the mesiobuccal roots of the second molars. The classification according to panoramic radiographs and CBCT images was the same in more than $90 \%$ of cases when there was no contact between the root apex and the sinus floor. When the panoramic radiograph showed root protrusion into the sinus, the CBCT images showed the same classification in $67.5 \%$ of second molars, $48.8 \%$ of first molars, and $53.3 \%$ of second premolars. There was a statistically significant relationship between interruption of the sinus floor on panoramic radiographs and root protrusion into the sinus on CBCT images.

Conclusion: The presence of root protrusion into the sinus on panoramic radiographs demonstrated a moderate ability to predict root protrusion into the maxillary sinus. Interruption of the maxillary sinus floor could be considered an indicator of actual root protrusion into the maxillary sinus. (Imaging Sci Dent 2020; 50: 309-18)

KEY WORDS: Maxillary Sinus; Molar; Radiography, Panoramic; Cone-Beam Computed Tomography

\section{Introduction}

The maxillary sinus is the largest paranasal sinus, and the topography of the maxillary sinus floor is extremely variable. The position of the roots relative to the sinus floor has several important clinical implications. ${ }^{1}$

The close relationship of the maxillary posterior teeth and maxillary sinus floor may result in various complications. A periapical or periodontal infection of maxillary molars and premolars may spread to the maxillary sinus

This work was supported by a 2-year research grant of Pusan National University. Received July 3, 2020; Revised August 17, 2020; Accepted September 1, 2020 *Correspondence to : Prof. Jae-Joon Hwang

Department of Oral and Maxillofacial Radiology, Pusan National University Dental Hospital, 20 Geumo-ro, Mulgeum-eup, Yangsan-si, Gyeongsangnam-do 50612 Korea

Tel) 82-55-360-5108,E-mail) softdent@pusan.ac.kr and cause odontogenic sinusitis. ${ }^{2-4}$ An oroantral communication or root displacement into the sinus cavity may occur after extraction of the first and second molars. ${ }^{5,6}$ The maxillary sinus is also relevant for endodontic procedures due to the introduction of endodontic instruments and materials beyond the apices of teeth in close proximity to the sinus. ${ }^{7}$ The extraction of roots protruding into the sinus could increase the associated risk of pneumatization. ${ }^{8}$ In addition, root protrusion into the maxillary sinus may influence root resorption or tipping during orthodontic treatment. ${ }^{9,10}$ Therefore, it is essential to assess the anatomical relationship of teeth relative to the maxillary sinus in order to avoid these complications.

The relationship between the maxillary sinus and the roots of the maxillary teeth can be assessed using vari- 
ous radiographic techniques. Panoramic radiography is commonly used to evaluate the anatomical relationship between the maxillary posterior teeth and the maxillary sinus. However, it has limitations, such as superimposition of anatomic structures, distortion, and the absence of cross-sectional information. ${ }^{11,12}$ Cone-beam computed tomography (CBCT) can provide 3-dimensional images and can be used to evaluate the relationship between the root and the maxillary sinus without distortion and superimposition of adjacent structures. ${ }^{13,14}$

Several studies have compared the relationship of the sinus floor to the roots on panoramic radiographs with CBCT images. ${ }^{15-19}$ When panoramic radiographs showed a distinct distance between the roots and the sinus, it was found to be unnecessary to order $\mathrm{CBCT}^{20}$ However, there was significant disagreement between panoramic radiographs and $\mathrm{CT}$ or CBCT images when the panoramic radiograph showed root protrusion into the sinus. ${ }^{18,21,22}$ Panoramic radiography was unreliable for evaluating the relationship between the roots and the maxillary sinus. ${ }^{16,20}$ The clinician must determine when it is necessary to order CBCT to assess the relationship between the maxillary sinus and the maxillary posterior teeth. $^{22}$

In previous studies, some instances of root protrusion into the sinus shown on panoramic radiographs were actually shown to be located laterally or medially to the sinus on CBCT images. ${ }^{15-18}$ Lopes et al. ${ }^{18}$ and Themkumkwun et al. ${ }^{19}$ investigated panoramic radiographic signs indicating actual protrusion of the roots into the maxillary sinus. They attempted to offer decision-making criteria regarding the need for CBCT scans before treatment planning in the posterior maxilla. ${ }^{18,19}$

The purpose of this study was to investigate correlations between findings on panoramic radiography and CBCT for evaluating the relationship between the maxillary sinus floor and the roots of maxillary posterior teeth. In addition, radiographic signs indicating actual root protrusion into the maxillary sinus were evaluated on panoramic radiographs.

\section{Materials and Methods}

The study protocol was approved by the Institutional Review Board of Pusan National University Dental Hospital. The subjects of this retrospective study were randomly selected from patients who visited Pusan National University Dental Hospital and underwent panoramic radiography and CBCT scans between 2013 and 2014. The inclusion criteria were patients aged from 20 to 50 years with the presence of all maxillary premolars and molars. Patients with patholog- ic lesions in the maxilla and with a history of orthodontic treatment were excluded from the study. The final sample group included data from 305 patients (162 men and 143 women; mean age, $28.6 \pm 7.3$ years; age range, 20 to 50 years). A total of 2,440 teeth were selected for the study, including 1,220 molars and 1,220 premolars.

All panoramic radiographs were taken using a Proline XC machine (Planmeca Co., Helsinki, Finland). CBCT scans were performed using a PaX-Zenith 3D (Vatech Co., Hwaseong, Korea) with settings of 5.2-5.7 mA, 106-110 $\mathrm{kV}$, an exposure time of $24 \mathrm{~s}$, a voxel size of $0.2 \mathrm{~mm}$, and a field of view of $16 \times 14 \mathrm{~cm}$. The CBCT data were saved in the Digital Imaging and Communications in Medicine format, and the images were analyzed using Ez3D Plus Professional CBCT software (Vatech Co., Hwaseong, Korea). Only patients with clear images from both radiographic techniques were included in this study.

All images were evaluated by a single oral and maxillofacial radiologist. The panoramic radiographs and CBCT images were assessed as separate subsets in a random sequence. Study images were evaluated twice at an interval of 4 weeks. Intra-observer reliability was assessed using the kappa statistic.

The relationship between the maxillary posterior teeth and the maxillary sinus floor was evaluated according to the criteria established by Jung and Cho. ${ }^{15}$ On the panoramic radiographs, the relationship of the root to the maxillary sinus floor was classified into three types: type 0 , the root was not in contact with the maxillary sinus floor; type 1 , the root was in contact with the cortical border of the sinus; and type 3 , the root apex projected into the sinus cavity (Fig. 1).

In addition, the panoramic radiographs were assessed for interruption of the cortex of the maxillary sinus floor, which Lopes et al. ${ }^{18}$ suggested to be a panoramic radiographic sign of root protrusion into the maxillary sinus (Fig. 2).

On the CBCT cross-sectional images, the relationship between the roots and the maxillary sinus floor was classified into 4 types: type 0 , the root was separate from the sinus floor; type 1 , the root was in close contact with the sinus floor; type 2 , the root projected laterally along the sinus cavity, but was actually lateral or medial to it; and type 3 , the root projected into the sinus cavity (Fig. 3). On the panoramic radiographs, type 2 was included in type 3 because it was difficult to distinguish between types 2 and 3 on the 2-dimensional panoramic radiographs.

For assessing the root-sinus relationship, a single score was obtained for each tooth on the panoramic radiographs 

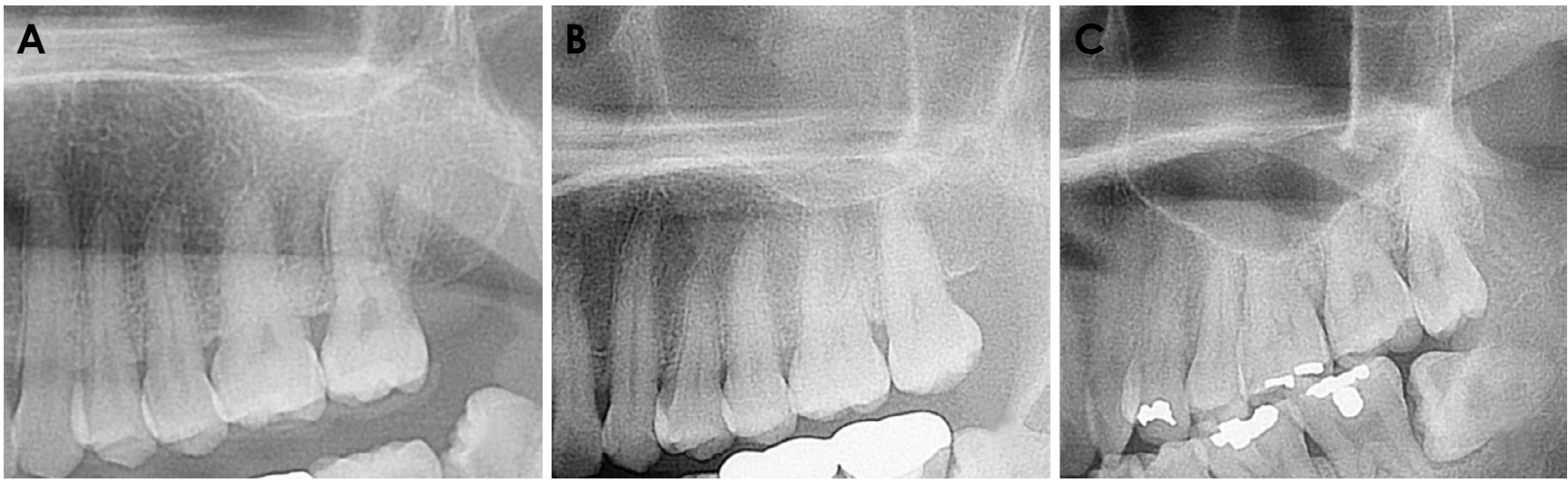

Fig. 1. The relationship between the maxillary sinus floor and the roots on panoramic radiographs. Type 0: the root is not in contact with the maxillary sinus floor; type 1: the root is in contact with the cortical border of the sinus; and type 3: the root apex projects into the sinus cavity.
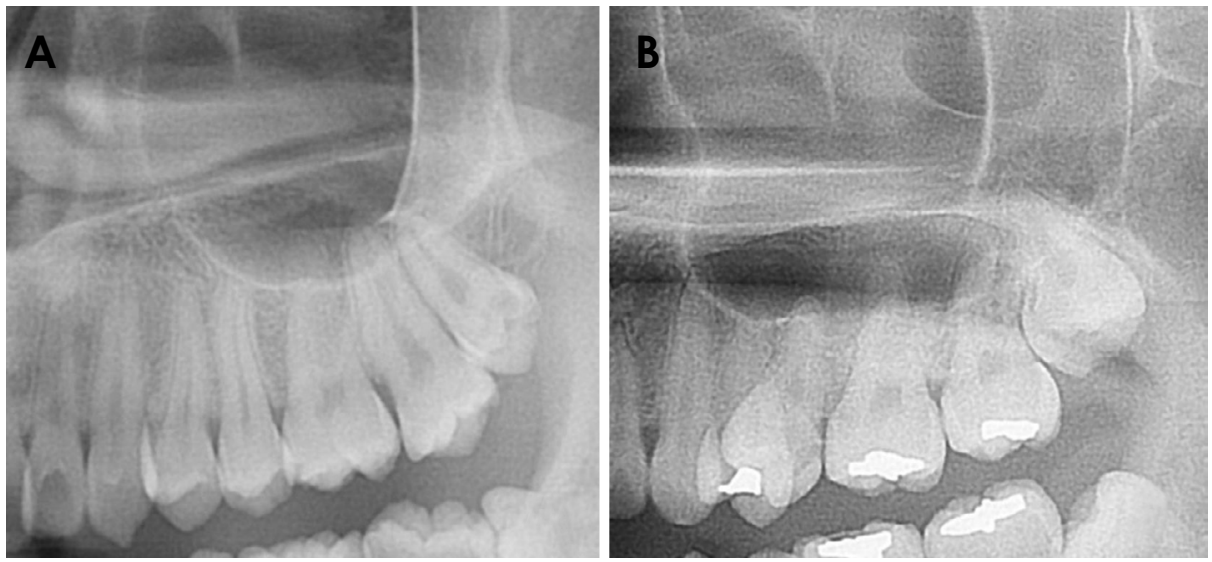

Fig. 2. Interruption of the cortex of the maxillary sinus floor on panoramic radiographs. A: No interruption of the sinus floor; B: interruption of the sinus floor.
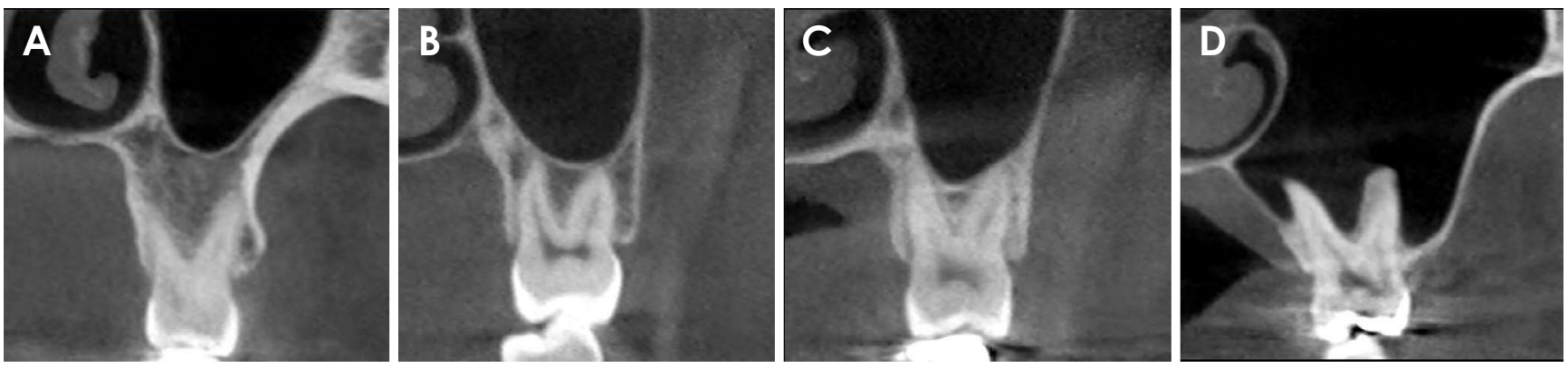

Fig. 3. Cone-beam computed tomographic images show 4 types of relationship between the root and the sinus floor. A: Type 0 , the root is separate from the sinus floor; B: type 1 , the root is in contact with the sinus floor; C: type 2 , the root projects laterally along the sinus cavity, but is outside the sinus borders; and D: type 3, the root projects into the sinus cavity.

and for each root of the tooth on the CBCT images. On the CBCT images, the maxillary premolars were evaluated as only a single root because the roots of most premolars were fused, and each maxillary molar root was classified in terms of the above types.

On the CBCT images, root protrusion of the maxillary molars into the maxillary sinus was classified according to the following 5 subtypes, based on the positional relationships of the buccal and palatal roots with the sinus floor: B2P3 (buccal root type 2, palatal root type 3); B3P0 (buccal root type 3, palatal root type 0 ); B3P1 (buccal root type 3 , palatal root type 1); B3P2 (buccal root type 3, palatal root type 2); B3P3 (buccal root type 3, palatal root type 3) (Fig. $4)$. 

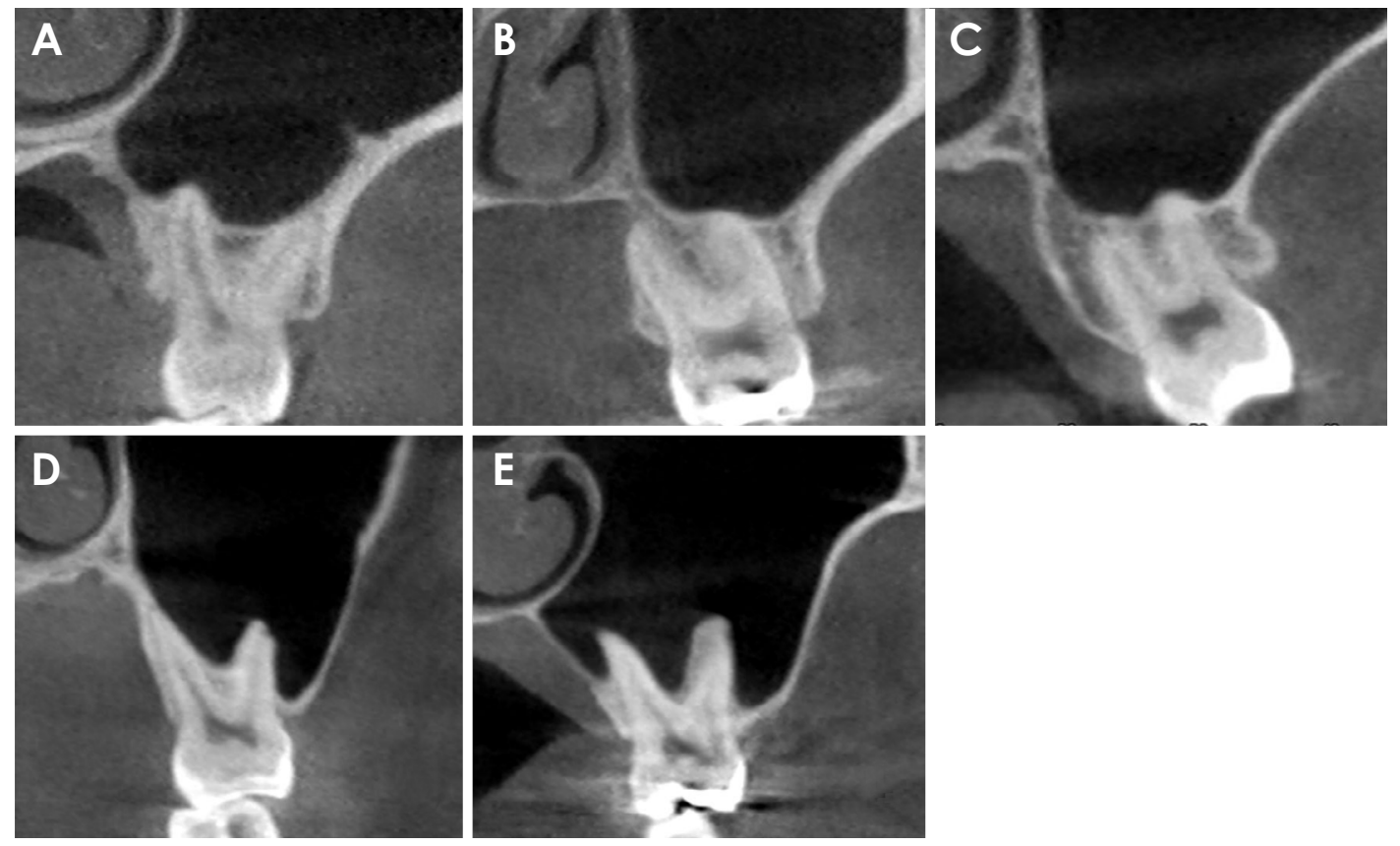

Fig. 4. The root protrusions of the maxillary molars were classified into 5 subtypes according to the combined types of the buccal and palatal roots. A: B2P3 (buccal root type 2, palatal root type 3); B: B3P0 (buccal root type 3 and palatal root type 0); C: B3P1 (buccal root type 3 and palatal root type 1); D: B3P2 (buccal root type 3 and palatal root type 2); E: B3P3 (buccal root type 3 and palatal root type 3 ).

Table 1. The relationship of the maxillary posterior teeth with the maxillary sinus floor on panoramic radiographs (number and percentage)

\begin{tabular}{lcccc}
\hline & Type 0 & Type 1 & Type 3 & Total \\
\hline Maxillary second molar & $68(11.1)$ & $111(18.2)$ & $431(70.7)$ & $610(100.0)$ \\
Maxillary first molar & $86(14.1)$ & $22(3.6)$ & $502(82.3)$ & $610(100.0)$ \\
Maxillary second premolar & $226(37.0)$ & $232(38.0)$ & $152(24.9)$ & $610(100.0)$ \\
Maxillary first premolar & $483(79.2)$ & $89(14.6)$ & $38(6.2)$ & $610(100.0)$ \\
\hline \multicolumn{1}{c}{ Total } & $863(35.4)$ & $455(18.6)$ & $1122(46.0)$ & $2440(100.0)$ \\
\hline
\end{tabular}

Contingency cross-tables with scores given for panoramic radiographic images and $\mathrm{CBCT}$ images were created. Information from the CBCT images was used as the reference standard. In addition, the positive and negative predictive values of the panoramic radiographs were calculated. The chi-square test was used to determine the significance of relationships between actual root projection into the sinus and interruption of the sinus floor cortex. $P$ values less than 0.05 were considered to indicate statistical significance. Statistical analyses were performed using SPSS version 25.0 (IBM Corp., Armonk, NY, USA).

\section{Results}

In total, 2,440 maxillary premolars and molars from 305 subjects were evaluated on panoramic radiographs and
CBCT images. The kappa values for intra-examiner reliability were 0.930 and 0.933 in the assessment of the panoramic radiographs and $\mathrm{CBCT}$ images, respectively.

On the panoramic radiographs, most molars showed a type 3 root-sinus relationship. Type 0 was most commonly seen in the first premolars and type 1 was more often found in the second premolars (Table 1).

The root-sinus relationships observed in the CBCT images were classified into 4 types. In all roots of second molars, type 3 was the most common (33.9\%), followed by type $1(28.6 \%)$. Among second molars, $543(89.0 \%)$ had 3 roots, $41(6.7 \%)$ had 2 roots, and $26(4.3 \%)$ had 1 fused root. When each root was classified based on its relationship with the sinus floor, type 3 occurred most frequently in the mesiobuccal roots of the second molars (48.4\%) and occurred least frequently in the palatal roots of the second 
Table 2. The relationship between the roots of maxillary second molars and the sinus floor on cone-beam computed tomographic images (number and percentage)

\begin{tabular}{|c|c|c|c|c|c|c|c|}
\hline \multirow{2}{*}{ Second molar } & \multicolumn{3}{|c|}{ Three roots } & \multicolumn{2}{|c|}{ Two roots } & \multirow{2}{*}{$\begin{array}{c}\text { One root } \\
\text { Root }\end{array}$} & \multirow{2}{*}{ Total } \\
\hline & Mesiobuccal root & Distobuccal root & Palatal root & Buccal root & Palatal root & & \\
\hline Type 0 & $63(11.6)$ & $80(14.7)$ & $178(32.8)$ & $4(9.8)$ & $18(43.9)$ & $5(19.2)$ & $348(20.0)$ \\
\hline Type 1 & $175(32.2)$ & $180(33.1)$ & $118(21.7)$ & $15(36.6)$ & $7(17.1)$ & $2(7.7)$ & $497(28.6)$ \\
\hline Type 2 & $42(7.7)$ & $55(10.1)$ & $179(33.0)$ & $11(26.8)$ & $10(24.4)$ & $7(26.9)$ & $304(17.5)$ \\
\hline Type 3 & $263(48.4)$ & $228(42.0)$ & $68(12.5)$ & $11(26.8)$ & $6(14.6)$ & $12(46.2)$ & $588(33.9)$ \\
\hline Total & $543(100.0)$ & $543(100.0)$ & $543(100.0)$ & $41(100.0)$ & $41(100.0)$ & $26(100.0)$ & $1737(100.0)$ \\
\hline
\end{tabular}

Table 3. The relationship between the roots of the maxillary first molars and the sinus floor on cone-beam computed tomographic images (number and percentage)

\begin{tabular}{|c|c|c|c|c|}
\hline First molar & Mesiobuccal root & Distobuccal root & Palatal root & Total \\
\hline Type 0 & $101(16.6)$ & $105(17.2)$ & $128(21.0)$ & $334(18.3)$ \\
\hline Type 1 & $170(27.9)$ & $162(26.6)$ & $44(7.2)$ & $376(20.5)$ \\
\hline Type 2 & $139(22.8)$ & $153(25.1)$ & $263(43.1)$ & $555(30.3)$ \\
\hline Type 3 & $200(32.8)$ & $190(31.1)$ & $175(28.7)$ & $565(30.9)$ \\
\hline Total & $610(100.0)$ & $610(100.0)$ & $610(100.0)$ & $1830(100.0)$ \\
\hline
\end{tabular}

Table 4. The relationship between the roots of maxillary premolars and the sinus floor on cone-beam computed tomographic images (number and percentage)

\begin{tabular}{lcc}
\hline & Second premolar & First premolar \\
\hline Type 0 & $228(37.4)$ & $482(79.0)$ \\
Type 1 & $235(38.5)$ & $93(15.2)$ \\
Type 2 & $66(10.8)$ & $27(4.4)$ \\
Type 3 & $81(13.3)$ & $8(1.3)$ \\
\hline Total & $610(100.0)$ & $610(100.0)$ \\
\hline
\end{tabular}

molars (12.5\%). Type 0 was more frequent in palatal roots than in buccal roots (Table 2).

In all first molar roots, the prevalence of type $3(30.9 \%)$ was similar to that of type $2(30.3 \%)$. All the maxillary first molars were 3-rooted. In the first molars, type 2 was most frequent in the palatal roots (43.1\%) and type 3 was most frequent in the mesiobuccal roots (32.8\%) (Table 3). Type 0 was most commonly seen in the first premolars, and type 1 was more often found in the second premolars (Table 4).

According to the combined types defined by both buccal and palatal root configurations, root protrusion of the maxillary molars into the sinus on the CBCT images was divided into 5 subtypes. Buccal root protrusion was more fre-
Table 5. Subclassification of root protrusion into the maxillary sinus on cone-beam computed tomographic images (number and percentage)

\begin{tabular}{lcc}
\hline & $\begin{array}{c}\text { Maxillary } \\
\text { second molar }\end{array}$ & $\begin{array}{c}\text { Maxillary } \\
\text { first molar }\end{array}$ \\
\hline $\begin{array}{l}\text { Buccal root type 2, } \\
\text { palatal root type 3 } \\
\begin{array}{l}\text { Buccal root type 3, } \\
\text { palatal root type 0 }\end{array}\end{array}$ & $0(0.0)$ & $30(12.2)$ \\
$\begin{array}{l}\text { Buccal root type 3, } \\
\text { palatal root type 1 }\end{array}$ & $38(13.1)$ & $2(0.8)$ \\
$\begin{array}{l}\text { Buccal root type 3, } \\
\text { palatal root type 2 } \\
\text { Buccal root type 3, } \\
\text { palatal root type 3 }\end{array}$ & $41(14.1)$ & $2(0.8)$ \\
\hline \multicolumn{1}{c}{ Total } & $126(43.3)$ & $66(26.9)$ \\
\hline
\end{tabular}

quent than palatal root protrusion in the maxillary molars. B3P2 (buccal root type 3, palatal root type 2) was most frequent in second molars and $\mathrm{B} 3 \mathrm{P} 3$ (buccal root type 3 , palatal root type 3 ) was most frequent in first molars (Table 5).

The relationship between the maxillary posterior teeth and the sinus floor on the panoramic radiographs was com- 
Table 6. Comparison of the relationship of maxillary teeth in relation to the sinus floor on panoramic radiographs and cone-beam computed tomographic (CBCT) images (number and percentage)

\begin{tabular}{|c|c|c|c|c|c|}
\hline & \multirow{2}{*}{ CBCT } & \multicolumn{3}{|c|}{ Panoramic radiograph } & \multirow{2}{*}{ Total } \\
\hline & & Type 0 & Type 1 & Type 3 & \\
\hline \multirow[t]{5}{*}{ Second molar } & Type $0 *$ & $66(97.1)$ & $4(3.6)$ & $0(0.0)$ & $70(11.5)$ \\
\hline & Type $1^{\dagger}$ & $2(2.9)$ & $107(96.4)$ & $59(13.7)$ & $168(27.5)$ \\
\hline & Type $2^{\ddagger}$ & $0(0.0)$ & $0(0.0)$ & $81(18.8)$ & $81(13.3)$ \\
\hline & Type $3^{\S}$ & $0(0.0)$ & $0(0.0)$ & $291(67.5)$ & $291(47.7)$ \\
\hline & Subtotal & $68(100.0)$ & $111(100.0)$ & $431(100.0)$ & $610(100.0)$ \\
\hline \multirow[t]{5}{*}{ First molar } & Type $0^{*}$ & $84(97.7)$ & $4(18.2)$ & $5(1.0)$ & $93(15.2)$ \\
\hline & Type $1^{\dagger}$ & $2(2.3)$ & $18(81.8)$ & $55(11.0)$ & $75(12.3)$ \\
\hline & Type $2^{\neq}$ & $0(0.0)$ & $0(0.0)$ & $197(39.2)$ & $197(32.3)$ \\
\hline & Type $3^{\S}$ & $0(0.0)$ & $0(0.0)$ & $245(48.8)$ & $245(40.2)$ \\
\hline & Subtotal & $86(100.0)$ & $22(100.0)$ & $502(100.0)$ & $610(100.0)$ \\
\hline \multirow[t]{5}{*}{ Second premolar } & Type 0 & $223(98.7)$ & $5(2.2)$ & $0(0.0)$ & $228(37.4)$ \\
\hline & Type 1 & $3(1.3)$ & $227(97.8)$ & $5(3.3)$ & $235(38.5)$ \\
\hline & Type 2 & $0(0.0)$ & $0(0.0)$ & $66(43.4)$ & $66(10.8)$ \\
\hline & Type 3 & $0(0.0)$ & $0(0.0)$ & $81(53.3)$ & $81(13.3)$ \\
\hline & Subtotal & $226(100.0)$ & $232(100.0)$ & $152(100.0)$ & $610(100.0)$ \\
\hline \multirow[t]{5}{*}{ First premolar } & Type 0 & $480(99.4)$ & $2(2.2)$ & $0(0.0)$ & $482(79.0)$ \\
\hline & Type 1 & $3(0.6)$ & 87 (96.7) & $3(7.9)$ & $93(15.2)$ \\
\hline & Type 2 & $0(0.0)$ & $0(0.0)$ & $27(71.1)$ & $27(4.4)$ \\
\hline & Type 3 & $0(0.0)$ & $0(0.0)$ & $8(21.1)$ & $8(1.3)$ \\
\hline & Subtotal & $483(100.0)$ & $89(100.0)$ & $38(100.0)$ & $610(100.0)$ \\
\hline
\end{tabular}

$*$ : all roots type $0,{ }^{\dagger}$ : highest type is type $1,{ }^{\dagger}$ : highest type is type $2,{ }^{\S}$ : highest type is type 3

pared with that on the CBCT images. The classification of the panoramic radiographs and $\mathrm{CBCT}$ images were the same in over $90 \%$ of cases when there was no contact between the root apex and the sinus floor (type 0 ). When the panoramic radiographs showed root protrusion into the sinus (type 3), the CBCT images had the same classification in $67.5 \%$ of second molars, $48.8 \%$ of first molars, $53.3 \%$ of second premolars, and $21.1 \%$ of first premolars. Among the cases of type 3 classification on the panoramic radiographs, $18.8 \%$ of second molars and $39.2 \%$ of first molars were classified as having a root projecting laterally (type 2) on the CBCT images (Table 6).

The negative predictive value was 0.971 and 0.977 for the maxillary second molars and first molars, respectively. When the root apex was separate from the sinus floor, the panoramic radiographs had a high probability of predicting this finding. The positive predictive value was 0.675 and 0.488 for the maxillary second molars and first molars, respectively. The finding of root protrusion into the sinus on the panoramic radiographs had a moderate ability to predict root protrusion into the maxillary sinus. The positive predictive value was not evaluated for the first premolars because the frequency of root protrusion was very low in the first premolars (Table 6).

Interruption of the sinus floor as an indicator of root protrusion into the sinus floor was evaluated on the panoramic radiographs. Most cases of root protrusion into the sinus on CBCT images showed discontinuities of the maxillary sinus floor on panoramic radiographs (Tables 7 and 8). Most instances of type 2 classifications showed no interruption of the sinus floor on the panoramic radiographs. The chisquare test showed a statistically significant relationship between root projection into the sinus and interruption of the sinus floor cortex $(P<0.05)$.

\section{Discussion}

In this study, the relationship between maxillary posterior teeth and the sinus floor on panoramic radiographs was compared with that on CBCT images, and the panoramic radiographic signs indicating root protrusion into the maxillary sinus were determined. 
Table 7. Relationship between interruption of the cortex of the maxillary sinus floor on panoramic radiographs and root protrusion of maxillary molars into the sinus on cone-beam computed tomographic (CBCT) images (number and percentage)

\begin{tabular}{|c|c|c|c|c|}
\hline & \multirow{2}{*}{ CBCT } & \multicolumn{2}{|c|}{ Panoramic radiograph } & \multirow{2}{*}{ Total } \\
\hline & & Interruption & No interruption & \\
\hline \multirow[t]{5}{*}{ Second molar } & Type $0 *$ & $0(0.0)$ & $70(100.0)$ & $70(100.0)$ \\
\hline & Type $1^{\dagger}$ & $4(2.4)$ & $164(97.6)$ & $168(100.0)$ \\
\hline & Type $2^{\ddagger}$ & $3(3.7)$ & $78(96.3)$ & $81(100.0)$ \\
\hline & Type $3^{\S}$ & $242(83.2)$ & $49(16.8)$ & $291(100.0)$ \\
\hline & Subtotal & $249(40.8)$ & $361(59.2)$ & $610(100.0)$ \\
\hline \multirow[t]{5}{*}{ First molar } & Type $0^{*}$ & $0(0.0)$ & $93(100.0)$ & $93(100.0)$ \\
\hline & Type $1^{\dagger}$ & $0(0.0)$ & $75(100.0)$ & $75(100.0)$ \\
\hline & Type $2^{\dagger}$ & $11(5.6)$ & $186(94.4)$ & $197(100.0)$ \\
\hline & Type $3^{\S}$ & $204(83.3)$ & $41(16.7)$ & $245(100.0)$ \\
\hline & Subtotal & $215(35.2)$ & $395(64.8)$ & $610(100.0)$ \\
\hline
\end{tabular}

*: all roots type $0,{ }^{\dagger}$ : highest type is type $1,{ }^{\dagger}$ : highest type is type $2,{ }^{\S}$ : highest type is type 3

Table 8. Relationship between interruption of the cortex of the maxillary sinus floor on panoramic radiographs and root protrusion of maxillary premolars into the sinus on cone-beam computed tomographic (CBCT) images (number and percentage)

\begin{tabular}{|c|c|c|c|c|}
\hline & \multirow{2}{*}{ СBCT } & \multicolumn{2}{|c|}{ Panoramic radiograph } & \multirow{2}{*}{ Total } \\
\hline & & Interruption & No interruption & \\
\hline \multirow[t]{5}{*}{ Second premolar } & Type 0 & $0(0.0)$ & $228(100.0)$ & $228(100.0)$ \\
\hline & Type 1 & $1(0.4)$ & $234(99.6)$ & $235(100.0)$ \\
\hline & Type 2 & $3(4.5)$ & $63(95.5)$ & $66(100.0)$ \\
\hline & Type 3 & $65(80.2)$ & $16(19.8)$ & $81(100.0)$ \\
\hline & Subtotal & $68(11.1)$ & $542(88.9)$ & $610(100.0)$ \\
\hline \multirow[t]{5}{*}{ First molar } & Type 0 & $0(0.0)$ & $482(100.0)$ & $482(100.0)$ \\
\hline & Type 1 & $1(1.1)$ & $92(98.9)$ & $93(100.0)$ \\
\hline & Type 2 & $3(11.1)$ & $24(88.9)$ & $27(100.0)$ \\
\hline & Type 3 & $4(50.0)$ & $4(50.0)$ & $8(100.0)$ \\
\hline & Subtotal & $8(1.3)$ & $602(98.7)$ & $610(100.0)$ \\
\hline
\end{tabular}

Many studies have examined the prevalence of roots protruding into the maxillary sinus, with various results. Several studies found that the mesiobuccal root of the maxillary second molar had the highest rate of protrusion into the maxillary sinus floor. ${ }^{18,23-28}$ Other studies reported that the palatal root of the first molar most frequently protruded into the sinus. ${ }^{19,29-32}$ Our results revealed that the type 3 (root protrusion into the sinus) configuration occurred most frequently in the mesiobuccal root of maxillary second molars (48.4\%), while type 2 occurred most frequently in the palatal root of maxillary first molars (43.1\%). Previous studies have reported that the palatal roots of second molars exhibited the lowest incidence of protrusion into the sinus. ${ }^{29,30}$ In our study, similar to previous studies, protrusion of roots into the sinus occurred least frequently in the palatal roots of second molars (12.5\%).

Many studies have assessed the relationship between the maxillary sinus and roots using various criteria. Several studies have evaluated the roots of maxillary teeth according to 4 types: no touching (type 0 ), touching the cortical borders of the sinus (type 1), projecting laterally along the sinus cavity (type 2), and protruding into the sinus (type 3)..$^{17,18,33,34}$ Other studies evaluated the roots of maxillary teeth according to 3 types: no touching (type 0 ), contact with the sinus floor (types 1 and 2, treated as 1 group), and penetrating into the sinus floor (type 3). ${ }^{16,19,26,29,32,35,36}$ Our study classified the relationship into 4 types. Therefore, it was difficult to compare the 2 classification systems (4 
types and 3 types) when evaluating type 1 and type 2 .

Many studies have reported that the type 0 relationship was most commonly observed. ${ }^{20,22,23,25,28,32}$ Other studies showed that type 0 was most frequently observed in premolars and type 3 in molars. ${ }^{16,18,19,26,34}$ Differences in reported sinus-root relationships might be due to ethnicity or methodology. ${ }^{19}$ Our study found that type 0 was most frequent in first premolars, type 1 was more frequent in second premolars, and type 3 , in which the root apex projected into the maxillary sinus, was most frequent in first and second molars, as reported by previous studies. $16,18,19,26,34$

In the present study, the combined types of buccal and palatal roots in maxillary molars were evaluated. Shokri et al. ${ }^{34}$ reported that palatal root protrusion of maxillary molars was more common, and other studies reported that buccal root protrusion was more frequent. ${ }^{24,25,33}$ In this study, buccal protrusion (B3P0, B3P1, B3P2) was more common than palatal root protrusion (B2P3) (Table 5).

Previous studies have reported good agreement for roots that were not in contact with the maxillary sinus floor on panoramic radiographs and CT or CBCT images. ${ }^{17,18,20,21,22}$ In our results, type 0 showed high agreement between panoramic radiographs and CBCT images, while the other types showed low agreement. In this study, the high negative predictive values indicated that CBCT is not necessary when panoramic radiographs show that the root is not in contact with the maxillary sinus. On panoramic radiographs, it was difficult to assess 3D structures when the root apex was laterally or medially positioned to the sinus. ${ }^{18}$ In our study, when panoramic radiographs showed root protrusion into the sinus (type 3), $18.8 \%$ of second molars and $39.2 \%$ of first molars were classified as having the root projecting laterally (type 2) on CBCT images.

When a panoramic radiograph shows that a root projects into the sinus, a CBCT scan should be requested, considering that it involves actual root protrusion. ${ }^{18}$ Therefore, we evaluated panoramic radiographic signs indicating actual root protrusion. Previous studies have proposed panoramic radiographic signs that could alert the dental clinician to possible root protrusions into the maxillary sinus. ${ }^{18,19}$ Lopes et al. ${ }^{18}$ reported 5 panoramic signs of root protrusion into the maxillary sinus, as follows: projection of the root apices, interruption of the maxillary sinus floor, absence of the lamina dura, darkening of the root apices, and a superiorly curving sinus floor enveloping the associated tooth root. They found that the projection of the root into the sinus and the interruption of the cortex of the maxillary sinus floor were statistically relevant indicators. ${ }^{18}$ Themkumkwun et al. ${ }^{19}$ modified one of the panoramic radiographic signs from the study of Lopes et al. ${ }^{18}$ by investigating the periodontal ligament space instead of evaluating the lamina dura due to the difficulty of identifying the radiopaque line of the lamina dura on panoramic images. ${ }^{19}$ They demonstrated that projection of the root into the sinus and darkening of the involved root apices on panoramic images were significant high-risk signs of root protrusion into the maxillary sinus. ${ }^{19}$

Although we tried to assess all panoramic radiographic signs that previous researchers ${ }^{18,19}$ evaluated, it was difficult to determine absence of the lamina dura and periodontal ligament space, darkening of root apices, and upward curving of the sinus floor enveloping the root because of superimposition, image distortion, and lack of sharpness on panoramic radiographs. Therefore, of these panoramic radiographic signs, we evaluated root projection into the sinus and interruption of the sinus floor.

The CBCT images were less likely to be classified as showing protrusion than the panoramic radiographs because the root projection length on the panoramic radiographs was larger than the root protrusion length on the CT or CBCT images. ${ }^{17,21}$ In our result, when the panoramic radiographs showed root protrusion into the sinus, $67.5 \%$ of second molars and $48.8 \%$ of first molars showed actual root protrusion into the sinus, while the others showed a lower classification grade on CBCT images. Our study found interruptions of the maxillary sinus floor in $83 \%$ of the maxillary molars with actual root protrusion into the maxillary sinus. A statistically significant relationship was observed between actual root protrusion into the sinus and interruption of the sinus floor, as in a previous study. ${ }^{18}$

In conclusion, the mesiobuccal roots of second molars had the highest rate of protrusion into the maxillary sinus floor. Panoramic radiography was reliable when the root was not in contact with the sinus floor. The finding of root protrusion into the sinus on panoramic radiographs demonstrated a moderate ability to predict root protrusion into the maxillary sinus. Interruption of the maxillary sinus floor could be considered as an indicator of actual root protrusion into the maxillary sinus.

\section{Conflicts of Interest: None}

\section{References}

1. Terlemez A, Tassoker M, Kizilcakaya M, Gulec M. Comparison of cone-beam computed tomography and panoramic radiography in the evaluation of maxillary sinus pathology related to maxillary posterior teeth: do apical lesions increase the risk of maxillary sinus pathology? Imaging Sci Dent 2019; 49: 
115-22.

2. Maillet M, Bowles WR, McClanahan SL, John MT, Ahmad M. Cone-beam computed tomography evaluation of maxillary sinusitis. J Endod 2011; 37: 753-7.

3. Nair UP, Nair MK. Maxillary sinusitis of odontogenic origin: cone-beam volumetric computerized tomography-aided diagnosis. Oral Surg Oral Med Oral Pathol Oral Radiol Endod 2010; 110: e53-7.

4. Ferguson M. Rhinosinusitis in oral medicine and dentistry. Aust Dent J 2014; 59: 289-95.

5. Güven O. A clinical study on oroantral fistulae. J Craniomaxillofac Surg 1998; 26: 267-71.

6. Punwutikorn J, Waikakul A, Pairuchvej V. Clinically significant oroantral communications - a study of incidence and site. Int J Oral Maxillofac Surg 1994; 23: 19-21.

7. Hauman CH, Chandler NP, Tong DC. Endodontic implications of the maxillary sinus: a review. Int Endod J 2002; 35 : 127-41.

8. Sharan A, Madjar D. Maxillary sinus pneumatization following extractions: a radiographic study. Int J Oral Maxillofac Implants 2008; 23: 48-56.

9. Daimaruya T, Takahashi I, Nagasaka H, Umemori M, Sugawara J, Mitani H. Effects of maxillary molar intrusion on the nasal floor and tooth root using the skeletal anchorage system in dogs. Angle Orthod 2003; 73: 158-66.

10. Oh H, Herchold K, Hannon S, Heetland K, Ashraf G, Nguyen $\mathrm{V}$, et al. Orthodontic tooth movement through the maxillary sinus in an adult with multiple missing teeth. Am J Orthod Dentofacial Orthop 2014; 146: 493-505.

11. Reddy MS, Mayfield-Donahoo T, Vanderven FJ, Jeffcoat MK. A comparison of the diagnostic advantages of panoramic radiography and computed tomography scanning for placement of root form dental implants. Clin Oral Implants Res 1994; 5: 229-38.

12. Tyndall DA, Brooks SL. Selection criteria for dental implant site imaging: a position paper of the American Academy of Oral and Maxillofacial Radiology. Oral Surg Oral Med Oral Pathol Oral Radiol Endod 2000; 89: 630-7.

13. Weiss R 2nd, Read-Fuller A. Cone beam computed tomography in oral and maxillofacial surgery: an evidence-based review. Dent J (Basel) 2019; 7: E52.

14. Horner K, O’Malley L, Taylor K, Glenny AM. Guidelines for clinical use of CBCT: a review. Dentomaxillofac Radiol 2015; 44: 20140225.

15. Jung YH, Cho BH. Comparison of panoramic radiography and cone beam computed tomography for assessing the relationship between the maxillary sinus floor and maxillary molars. Korean J Oral Maxillofac Radiol 2009; 39: 69-73.

16. Hassan BA. Reliability of periapical radiographs and orthopantomograms in detection of tooth root protrusion in the maxillary sinus: correlation results with cone beam computed tomography. J Oral Maxillofac Res 2010; 1: e6.

17. Shahbazian M, Vandewoude C, Wyatt J, Jacobs R. Comparative assessment of panoramic radiography and $\mathrm{CBCT}$ imaging for radiodiagnostics in the posterior maxilla. Clin Oral Investig 2014; 18: 293-300.

18. Lopes LJ, Gamba TO, Bertinato JV, Freitas DQ. Comparison of panoramic radiography and $\mathrm{CBCT}$ to identify maxillary posterior roots invading the maxillary sinus. Dentomaxillofac Radiol 2016; 45: 20160043.

19. Themkumkwun S, Kitisubkanchana J, Waikakul A, Boonsiriseth K. Maxillary molar root protrusion into the maxillary sinus: a comparison of cone beam computed tomography and panoramic findings. Int J Oral Maxillofac Surg 2019; 48: 1570-6.

20. Sun W, Xia K, Tang L, Liu C, Zou L, Liu J. Accuracy of panoramic radiography in diagnosing maxillary sinus-root relationship: a systematic review and meta-analysis. Angle Orthod 2018; 88: 819-29.

21. Sharan A, Madjar D. Correlation between maxillary sinus floor topography and related root position of posterior teeth using panoramic and cross-sectional computed tomography imaging. Oral Surg Oral Med Oral Pathol Oral Radiol Endod 2006; 102: 375-81.

22. Kirkham-Ali K, La M, Sher J, Sholapurkar A. Comparison of cone-beam computed tomography and panoramic imaging in assessing the relationship between posterior maxillary tooth roots and the maxillary sinus: a systematic review. J Investig Clin Dent 2019; 10: e12402.

23. Pagin O, Centurion BS, Rubira-Bullen IR, Alvares Capelozza AL. Maxillary sinus and posterior teeth: accessing close relationship by cone-beam computed tomographic scanning in a Brazilian population. J Endod 2013; 39: 748-51.

24. Estrela C, Nunes CA, Guedes OA, Alencar AH, Estrela CR, Silva RG, et al. Study of anatomical relationship between posterior teeth and maxillary sinus floor in a subpopulation of the Brazilian central region using cone-beam computed tomography - part 2. Braz Dent J 2016; 27: 9-15.

25. Zhang X, Li Y, Zhang Y, Hu F, Xu B, Shi X, et al. Investigating the anatomical relationship between the maxillary molars and the sinus floor in a Chinese population using cone-beam computed tomography. BMC Oral Health 2019; 19: 282.

26. Zhang YQ, Yan XB, Meng Y, Zhao YN, Liu DG. Morphologic analysis of maxillary sinus floor and its correlation to molar roots using cone beam computed tomography. Chin J Dent Res 2019; 22: 29-36.

27. Razumova S, Brago A, Howijieh A, Manvelyan A, Barakat H, Baykulova M. Evaluation of the relationship between the maxillary sinus floor and the root apices of the maxillary posterior teeth using cone-beam computed tomographic scanning. J Conserv Dent 2019; 22: 139-43.

28. Pei J, Liu J, Chen Y, Liu Y, Liao X, Pan J. Relationship between maxillary posterior molar roots and the maxillary sinus floor: cone-beam computed tomography analysis of a western Chinese population. J Int Med Res 2020; 48: 300060520926896.

29. Tian XM, Qian L, Xin XZ, Wei B, Gong Y. An analysis of the proximity of maxillary posterior teeth to the maxillary sinus using cone-beam computed tomography. J Endod 2016; 42: 371-7.

30. Jang JK, Kwak SW, Ha JH, Kim HC. Anatomical relationship of maxillary posterior teeth with the sinus floor and buccal cortex. J Oral Rehabil 2017; 44: 617-25.

31. Nino-Barrera JL, Ardila E, Guaman-Pacheco F, Gamboa-Martinez L, Alzate-Mendoza D. Assessment of the relationship between the maxillary sinus floor and the upper posterior root tips: clinical considerations. J Investig Clin Dent 2018; 9: 
e12307.

32. Gu Y, Sun C, Wu D, Zhu Q, Leng D, Zhou Y. Evaluation of the relationship between maxillary posterior teeth and the maxillary sinus floor using cone-beam computed tomography. BMC Oral Health 2018; 18: 164.

33. Jung YH, Cho BH. Assessment of the relationship between the maxillary molars and adjacent structures using cone beam computed tomography. Imaging Sci Dent 2012; 42: 219-24.

34. Shokri A, Lari S, Yousef F, Hashemi L. Assessment of the relationship between the maxillary sinus floor and maxillary posterior teeth roots using cone beam computed tomography. J Contemp Dent Pract 2014; 15: 618-22.

35. Kilic C, Kamburoglu K, Yuksel SP, Ozen T. An assessment of the relationship between the maxillary sinus floor and the maxillary posterior teeth root tips using dental cone-beam computerized tomography. Eur J Dent 2010; 4: 462-7.

36. Ok E, Güngör E, Colak M, Altunsoy M, Nur BG, Ağlarci OS. Evaluation of the relationship between the maxillary posterior teeth and the sinus floor using cone-beam computed tomography. Surg Radiol Anat 2014; 36: 907-14. 